\title{
A Cellular Analysis of Inhibition in the Siphon Withdrawal Reflex of Aplysia
}

\author{
William G. Wright, ${ }^{a}$ Emilie A. Marcus, and Thomas J. Carew \\ Departments of Biology and Psychology, Yale University, New Haven, Connecticut 06520
}

Recent behavioral experiments examining the siphon withdrawal reflex of Aplysia have revealed inhibitory effects of strong tail shock, a stimulus commonly used as an unconditioned stimulus in studies of associative and nonassociative learning in Aplysia.

We utilized a reduced preparation to perform a cellular analysis of tail shock-induced inhibition in the siphon withdrawal reflex. First, we carried out behavioral studies that showed that the reduced preparation exhibits a siphon withdrawal reflex to water jet stimuli, and that tail shock produces inhibitory behavioral effects comparable to those in the intact animal: (1) strong shock produces transient inhibition of nonhabituated responses, and (2) a habltuated response is facilitated by weak shock, but not by strong shock, suggesting that increasing tail shock intensity recruits the inhibitory process that competes with facilitation of habituated reflexes. Next, we carried out cellular studies that showed that the amplitude of the complex EPSP in siphon motor neurons elicited by water jet stimuli to the siphon also exhibits the inhibitory patterns produced by tail shock: (1) the nondecremented complex EPSP (a neural correlate of a nonhabituated siphon withdrawal reflex) is significantly inhibited 90 sec after strong tail shock and recovers to preshock levels 10 min later, and (2) the decremented complex EPSP (a neural correlate of a habituated reflex) is significantly facilitated by weak shock, but is not facilitated by strong shock.

In addition to the complex EPSP, we simultaneously examined the monosynaptic connection between siphon sensory neurons and siphon motor neurons. The monosynaptic EPSP does not show the pattern of inhibitory modulation by tail shock exhibited by the siphon withdrawal reflex and the complex EPSP: (1) the nondecremented monosynaptic EPSP is not inhibited $90 \mathrm{sec}$ after strong shock, but tends to be above preshock levels; and (2) the decremented monosynaptic EPSP is facilitated by weak as well as strong tail shock.

Our results suggest that an important component of the

\footnotetext{
Received Aug. 24, 1990; revised Mar. 12, 1991; accepted Mar. 13, 1991.

We thank Diana Blazis, David Cook, Kent Fitzgerald, and Mark Stopfer for their helpful comments on the manuscript and Elizabeth McCance for excellent assistance in the behavioral experiments. This work was supported by National Institute of Mental Health National Research Service Award 1-F32-MH09397 to W.G.W., by a National Science Foundation graduate fellowship and National Institute of Mental Health National Research Service Award 1-F31-MH0987401-BPN-2 to E.A.M., and by National Science Foundation Grant BNS8311300 and Office of Naval Research Grant N00014-87-K-0381 to T.J.C.

Correspondence should be addressed to Thomas J. Carew, Department of Psychology, Yale University, P.O. Box 11 A Yale Station, New Haven, CT 06520.

- Present address: Biology Department, Colorado State University, Fort Collins, CO 80521 .
}

Copyright (C) 1991 Society for Neuroscience 0270-6474/91/112498-12\$03.00/0 inhibitory process triggered by strong tail shock is mediated by neural elements presynaptic to the siphon motor neurons. Because modulation of the monosynaptic connection between identified siphon sensory and siphon motor neurons does not parallel the tail shock-induced inhibitory patterns observed in the siphon withdrawal reflex and in the complex EPSP, other synaptic connections are likely to play an important role in mediating tail shock-induced inhibition in the siphon withdrawal reflex.

At both behavioral and cellular levels, a complete analysis of the processes that underlie learning requires understanding all of the possible effects of the stimuli used to produce the learning. In the marine mollusk Aplysia, a preparation well suited for a behavioral and cellular analysis of learning, an aversive electric shock to the tail has often been used as an unconditioned stimulus (US) to produce a variety of forms of both nonassociative and associative learning (Byrne, 1987; Carew, 1987; Hawkins et al., 1987). For a complete mechanistic understanding of learning in Aplysia when tail shock is used as a US, it is important to understand the cellular mechanisms underlying all of the behavioral effects of tail shock. Tail shock has long becn known to have facilitatory effects on a number of defensive reflexes, including siphon withdrawal, gill withdrawal, tail withdrawal, and escape locomotion, and in many cases a detailed understanding of the cellular basis of these facilitatory effects has emerged (Klein and Kandel, 1980; Bernier et al., 1982; Siegelbaum et al., 1982; Occor et al., 1986; Walsh and Byrne, 1989; Baxter and Byrne, 1989; for reviews, see Kandel and Schwartz, 1982; Byrne, 1987; Carew, 1987; Hawkins et al., 1987). Recently, however, it has become clear that tail shock can also have inhibitory effects in some of these same reflexes (KrontirisLitowitz et al., 1987; Mackey et al., 1987; Marcus et al., 1987, 1988; Rankin and Carew, 1987, 1989), In the present study, we have begun to explore the cellular basis of these inhibitory effects.

In addition to providing insights into cellular mechanisms of inhibition in Aplysia, this article and its companion (Fitzgerald and Carew, 1991) are also aimed at a more general objective. Inhibitory processing has figured prominently in several general theories of learning (Mackintosh, 1974). However, the detailed cellular mechanisms by which inhibitory and excitatory processes interact to give rise to behavioral outcomes predicted by specific learning theories are very poorly understood. Because restricted neural networks in Aplysia, such as the neural circuit for the siphon withdrawal reflex examined in this article, are known to support several forms of learning, an understanding of the cellular mechanisms by which excitatory and inhibitory processes interact in these networks may provide general in- 
sights into the specific roles that excitatory and inhibitory processes play in specific forms of learning.

Marcus et al. (1988) identified both excitatory and inhibitory effects of tail shock on the water jet-elicited siphon withdrawal reflex by systematically varying three parameters: (1) the initial state of the reflex (habituated or nonhabituated), (2) the strength of the modulatory tail shock, and (3) the time of testing after tail shock. A principal finding from that study was that strong tail shock recruited an inhibitory process, which could be observed directly as a transient decrease of a nonhabituated siphon withdrawal reflex (see also Krontiris-Litowitz et al., 1987; Mackey et al., 1987; Rankin and Carew, 1987, 1989). The inhibitory process could also be inferred from the observation that, when the siphon withdrawal reflex was habituated just prior to tail shock, weak tail shock produced robust facilitation of the habituated reflex (dishabituation), whereas strong shock produced no reflex facilitation. This suggested that increasing the tail shock intensity recruits the inhibitory process that competes with the facilitatory process of dishabituation (Marcus et al., 1988; see also Rankin and Carew, 1989).

Previous work on the siphon withdrawal reflex (Mackey et al., 1987) had proposed the monosynaptic connection between identified siphon sensory neurons (LE) and siphon motor neurons (LFS and LBS) as a possible locus mediating tail shockinduced inhibition. This suggestion was based on the observation that tail shock produced transient inhibition of the monosynaptic EPSP from sensory to motor neurons; the inhibition later gave way to facilitation. However, as pointed out by Mackey et al. (1987), though the sequence of the synaptic changes paralleled that of the behavioral changes, the time course of these monosynaptic changes differed from that of the behavioral changes. Specifically, inhibition of the monosynaptic connection gave way to facilitation within $90 \mathrm{sec}$ after tail shock, whereas behavioral inhibition of the reflex was observed to persist for several minutes after shock (Mackey et al., 1987). Thus, the synaptic changes observed at the level of the monosynaptic connection did not appear to account fully for the observed behavioral inhibition, implying that other cellular loci might be involved. In this article, we present a cellular analysis that establishes neuronal correlates of the tail shock-induced inhibitory process in central neurons that mediate the siphon withdrawal reflex in Aplysia. We provide evidence that the inhibitory process in the siphon withdrawal reflex is not directly mediated by the LE sensory neuron-motor neuron connection, but rather appears to rely on input from interneurons, or from other as yet unidentified sensory neurons.

Some of the results described in this article have previously been presented in preliminary form (Wright et al., 1988, 1989).

\section{Materials and Methods}

Preparation. Adult Aplysia weighing 75-125 gm were obtained from Marinus, Inc., Long Beach, CA. Animals were anesthetized by injection of $120 \mathrm{ml}$ of isotonic $\mathrm{MgCl}_{2}$, or by immersion in cold $\left(\approx 0^{\circ} \mathrm{C}\right)$ artificial sea water (ASW) for 30-50 min. The tail, mantle, gill, and siphon were dissected, leaving them attached to the CNS by their respective peripheral nerves: the tail via the paired $\mathrm{P} 9$ nerves, and the mantle/gill/siphon via the siphon nerve (Fig. 1). The tail and mantle organs were then pinned loosely in a Sylgard-lined dish. In order to purge the tail of $\mathrm{MgCl}_{2}$ and to deliver a supply of oxygen, the tail was constantly perfused with ASW solution ( $460 \mathrm{~mm} \mathrm{NaCl}, 55 \mathrm{~mm} \mathrm{MgCl}_{2}, 11 \mathrm{~mm} \mathrm{CaCl}, 10 \mathrm{~mm}$ $\mathrm{KCl}, 10 \mathrm{~mm}$ Tris) via a hypodermic needle. In the behavioral experiments, approximately $60 \mathrm{ml}$ of ASW was injected via hypodermic syringe into the siphon 15-30 min before the start of each experiment.

Protocol. The various stimulus paradigms used in our experiments

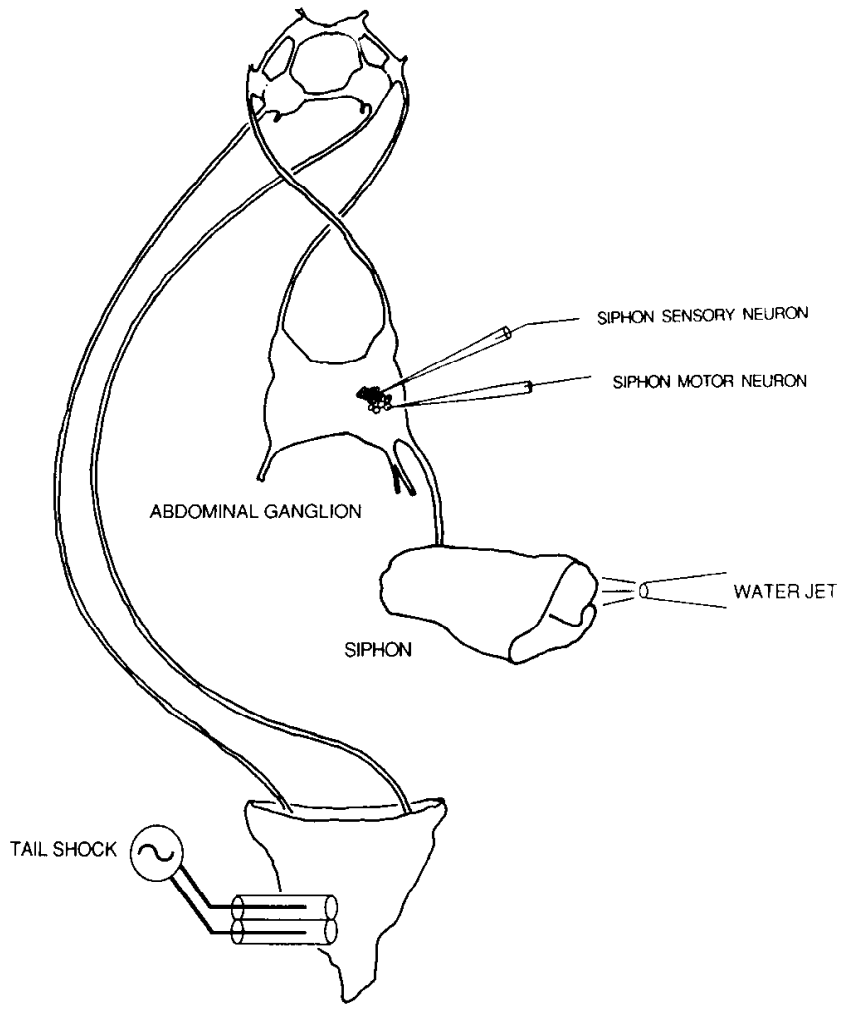

Figure 1. The reduced preparation used to analyze the neuronal correlates of inhibition. See Materials and Methods for details.

are illustrated in Figure 2. Stimulus protocols equivalent to previous experiments with intact animals were used (Marcus et al., 1988): (1) A nondecremented (nonhabituated) protocol consisted of four water jet stimuli (two pretest and two test stimuli) delivered to the siphon at a 10-min interstimulus interval (ISI). The water jet stimulus was produced by a Pico-Spritzer (General Valve Corp.), set at 25 psi and 70-msec duration, delivered with a pipette (i.d., $5 \mathrm{~mm}$ ) positioned approximately $5 \mathrm{~mm}$ from the internal surface of the siphon (see Fig. 1). This stimulus intensity was constant throughout each preparation. A strong electric shock (four 1-sec pulses of $50 \mathrm{~mA} \mathrm{AC}$, at a 1-sec interstimulus interval) was delivered to the tail $90 \mathrm{sec}$ before the first test stimulus. (2) The decremented (habituated) protocol was cquivalent to dishabituation training and consisted of 21 water jet stimuli delivered at a rate (100sec ISI) that produces habituation. Ninety seconds before the last water jet stimulus, an electric shock was delivered with one of two intensities: weak (a single 1-sec pulse of $10 \mathrm{~mA} \mathrm{AC}$ ) or strong (four $1-\mathrm{sec}$ pulses of $50 \mathrm{~mA} \mathrm{AC}$ ).

Behavioral experiments. In the nonhabituated protocol, animals were randomly assigned to shocked or unshocked groups. In the decremented protocol, animals were randomly assigned to weak- or strong-shock groups. Because some animals receiving strong shock produced ink, to maintain blind procedures we introduced ink taken from the ink gland of another animal into the chambers of all groups before the first postshock test. An observer blind to the specific experimental conditions scored the duration of each water jet-elicited siphon withdrawal reflex (see Marcus et al., 1988) throughout the experiment.

Cellular experiments. The abdominal ganglion was pinned ventral side up in 50:50 isotonic $\mathrm{MgCl}_{2}: \mathrm{ASW}$, and the left hemiganglion was desheathed. After rinsing the ganglion in ASW, a siphon motor neuron (LFS; Frost et al., 1988) and a siphon sensory neuron (LE; Byrne et al., 1974) were impaled with glass microelectrodes (10-20 M $\Omega$ ) filled with $3 \mathrm{M} \mathrm{KCI}$ (Fig. 1). Before each test, the motor neuron was hyperpolarized $40-50 \mathrm{mV}$ below rest to prevent spiking. During each test, we monitored the amplitude of two different synaptic inputs onto the motor neuron: (1) A complex (polysynaptic) EPSP was produced by a water jet stimulus to the siphon. Water jet intensity was reduced in the cellular experiments to permit stable long-term recordings; relative to the behavioral experiments the reduced intensity was still capable of eliciting a brisk discharge from the motor neurons at rest, even though it did not activate 
NON-DECREMENTED

(ISI = $10 \mathrm{~min})$

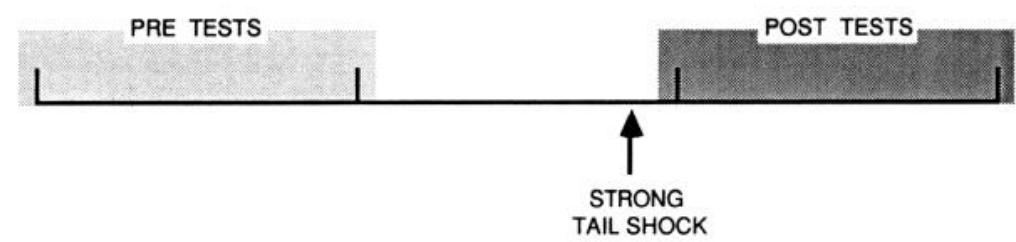

DECREMENTED

(ISI $=100 \mathrm{sec}$ )

Figure 2. Schematic illustration of the paradigms used to examine the inhibitory process. Each vertical tick mark represents a water jet stimulus to the siphon. Tail shock was delivered at the arrow. The responses that were used to calculate the pretest baseline and the posttests are indicated by different levels of shading.

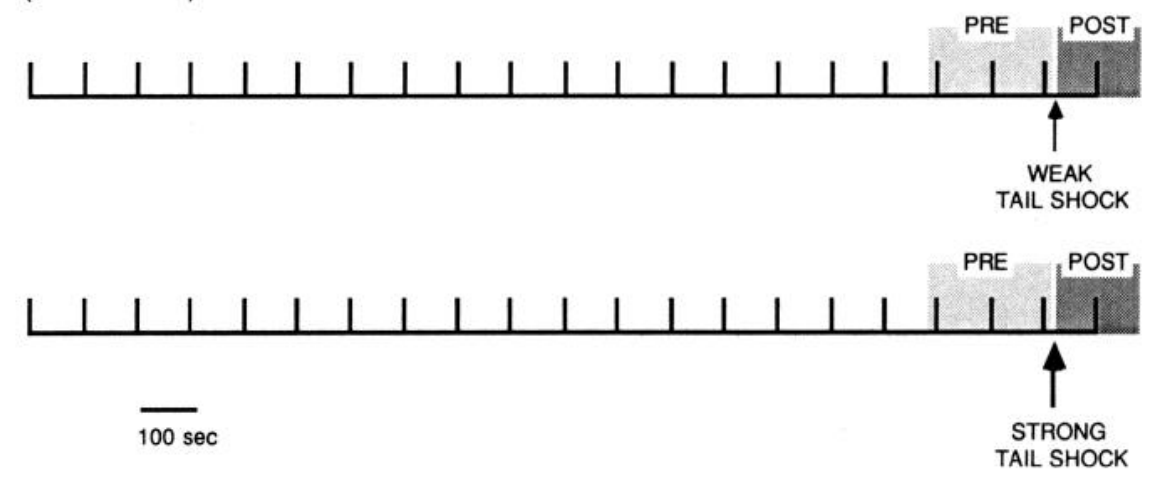

the LE sensory neurons. The amplitude of the complex EPSP was measured as the maximum depolarization occurring within $800 \mathrm{msec}$ after delivery of the water jet stimulus. (2) A monosynaptic EPSP was produced by a single action potential in the sensory neuron (elicited by injecting depolarizing current). Typically, the complex EPSP was tested first, followed $30 \mathrm{sec}$ later by a test of the monosynaptic EPSP; however, in some experiments the monosynaptic EPSP was tested first, followed within $10 \mathrm{sec}$ by a test of the complex EPSP. Earlier pilot studies had demonstrated that there was no effect of the order of presentation of the two stimuli. In a separate experiment, just prior to the water jetelicited complex EPSP, the input resistance of the hyperpolarized motor neuron was assessed by injection of $0.25 \mathrm{nA}$ of hyperpolarizing current and measurement of the resulting electrotonic potential.

Statistical analysis. All test responses are expressed as a percentage of baseline responding obtained by dividing the test scores by the median of the two preshock scores in the nondecremented protocol, or the last three preshock scores (trials 18-20) in the decremented protocol. Because some protocols gave rise to decremented behavioral and synaptic responses with amplitude scores approaching 0 , the resultant non-normal distribution of response amplitudes necessitated the use of nonparametric statistics. Between-group comparisons were made with the Wilcoxon two-sample test (test statistic $W$; Hollander and Wolfe, 1973); within-group comparisons were made with the Wilcoxon sign-rank test for repeated measures (test statistic $T^{+}$; Hollander and Wolfe, 1973). In some cases, within- and between-group differences were modest, only achieving statistical significance with a one-tailed test (the use of a onetailed test was appropriate because the direction of the effect had been predicted a priori). These few cases are indicated. In all other cases, probabilities are two-tailed. Data are expressed as medians \pm the interquartile range. The asymmetry of the interquartile range in some figures reflects the fact that this measure of variability need not be equally distributed around the median.

\section{Results}

\section{Behavioral analysis}

In order to carry out a cellular analysis of inhibitory modulation in the siphon withdrawal reflex, it was first important to demonstrate that the reduced preparation used for the cellular analysis (Fig. 1) exhibited the essential behavioral features of in- hibition that are observed in the intact animal (Marcus et al., 1988). To address this question, we explored inhibition in two ways: (1) by examining the effects of strong tail shock on nonhabituated responses, and (2) by examining the effects of both weak and strong tail shock on habituated reflex responses (see Fig. 2).

\section{Nonhabituated responses}

The siphon withdrawal reflex of two randomly assigned groups (shocked, $N=12$, and unshocked, $N=12$ ) was tested at a nonhabituating 10-min ISI before and after tail shock. As in the intact animal, stimulating the siphon at an interval of $10 \mathrm{~min}$ produced no habituation of the siphon withdrawal reflex between the first and second tests. The two pretests were averaged yielding a median duration of $4.9 \mathrm{sec}$ in both groups. Moreover, $90 \mathrm{sec}$ after strong tail shock, the reflex was markedly inhibited (median, $2.7 \mathrm{sec}, 55 \%$ of baseline; Fig. $3 A$, test 1 ). The inhibited reflex was significantly lower than preshock levels (sign-rank test; $N=12 ; T^{+}=2 ; p=0.004$ ) and was also significantly lower than the nonshocked control group (two-sample test; $N=12$; $W=106 ; p=0.012$ ). The reflex recovered significantly from tail shock-induced inhibition $10 \mathrm{~min}$ later (median, $4.7 \mathrm{sec}$, $95 \%$ of baseline; sign-rank test; $T^{+}=70 ; p=0.003$; Fig. $3 A$, test 2), at which time it was no longer significantly different from baseline levels (sign-rank test; $T^{+}=25 ; p=0.29$ ), nor from the nonshocked control group (two-sample test; $W=144 ; p=0.75$ ). Thus, in the reduced preparation, strong tail shock produces significant transient reflex inhibition comparable to that observed in intact animals (Marcus et al., 1988).

\section{Habituated responses}

To examine the effects of tail shock on habituated responses, the siphon withdrawal reflex was habituated by 20 repeated 


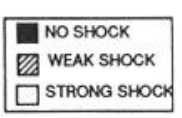

A NON-HABITUATED

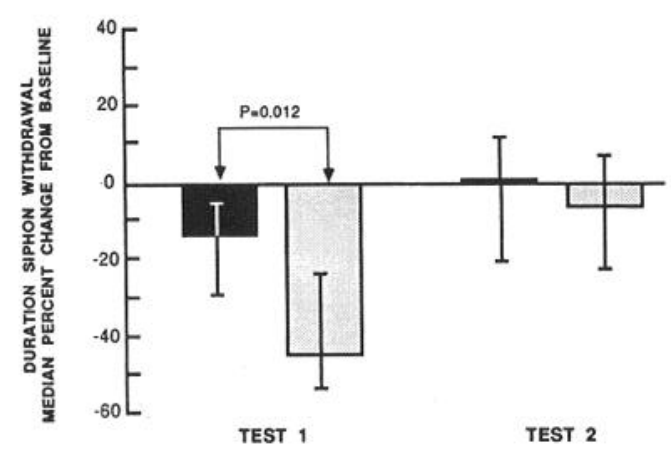

B HABITUATED

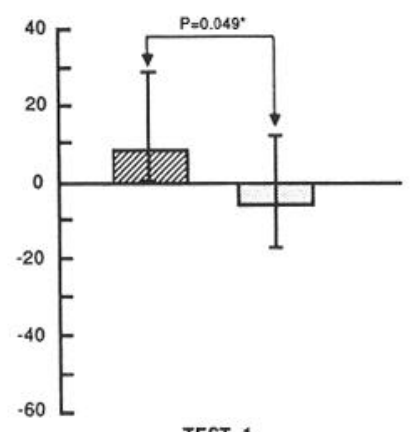

Figure 3. Tail shock-induced modulation of the siphon withdrawal reflex in the reduced preparation. Duration of siphon withdrawal in response to water jet stimuli is shown relative to the preshock baseline. $A$, Nonhabituated reflex: stimuli were delivered with a 10-min ISI. Data are expressed as percent change from the median of the two preshock tests. Strong shock $(N=12)$ produced significant inhibition of the reflex 90 sec postshock (TEST 1) compared to a nonshocked control group $(N=12)$. This inhibition recovered within 10 min (TEST 2). B, Habituated reflex: 20 water jet test stimuli were delivered with a 100 -sec ISI prior to tail shock. Tail shock was delivered $10 \mathrm{sec}$ after the 20 th siphon stimulus, and a single test stimulus (TEST 1) was given $90 \mathrm{sec}$ later. Data are expressed as percent change from the median of the last three preshock tests (pretests 18 20). Weak tail shock $(N=11)$ produced modest but significant facilitation in the siphon withdrawal reflex, whereas strong shock $(N=10)$ produced no significant change. The asterisk indicates a one-tailed probability value. In this and all subsequent figures, data are expressed as medians \pm the interquartile range. The asymmetry of the interquartile range in some figures reflects the fact that this measure of variability need not be equally distributed around the median.

water jet stimuli to the siphon $(N=21)$. This produced significant habituation from a preshock median duration of $5.2 \mathrm{sec}$ to a habituated median of $3.0 \mathrm{sec}$ (combining both groups' pretest responses; sign-rank test comparing last three responses to initial response; $\left.T^{+}=0 ; p<0.001\right)$. Half of the animals $(N=$ 11) then received weak tail shock, while the other half $(N=10)$ received strong shock. The behavioral response to the weak shock was a brief tail and siphon withdrawal; in response to the strong tail shock, both the tail and siphon withdrew much more vigorously and for a longer period of time, and in some cases inking occurred. In both conditions, the siphon returned to baseline prior to the posttest. The results are shown in Figure $3 B$. Weak tail shock produced modest but significant facilitation of the habituated reflex (median, 109\% of baseline; sign-rank test; $N=11 ; T^{+}=55 ; p=0.028$, one-tailed), while strong shock produced no facilitation (median, $95 \%$; sign-rank test; $N=10$; $T^{+}=20 ; p=0.49$, one-tailed; Fig. $3 B$ ). Moreover, there was a modest but significant difference between weak- and strongshock groups (two-sample test; $N=10,11 ; W=145 ; p=0.049$, one-tailed).

In summary, though the behavioral effects in the reduced preparation using the habituated protocol are modest, they are consistent with the observations in intact animals that weak tail shock facilitates habituated responses, whereas strong shock does not. Taken together with our results on the nondecremented reflex, these observations suggest that strong tail shock activates an inhibitory process that competes with the facilitatory process of dishabituation.

\section{Cellular analysis}

The results of the behavioral experiments described above demonstrate that strong tail shock produces an inhibitory pattern in the reduced preparation similar to that previously observed in the intact animal. We therefore used this preparation to search for central neuronal correlates of this reflex inhibition. Specifically, we examined (1) whether strong tail shock produces inhibition of nondecremented synaptic responses that recovers after $10 \mathrm{~min}$, and (2) whether decremented synaptic responses are facilitated by weak tail shock but not by strong tail shock.

\section{Nondecremented responses}

We first asked whether changes in nondecremented complex and monosynaptic EPSPs in siphon motor neurons paralleled the inhibition and recovery of the nonhabituated siphon withdrawal reflex after a strong tail shock. An example of our results is shown in Figure 4. The complex EPSP elicited by a water jet stimulus to the siphon at a 10 -min ISI was relatively stable in the two preshock tests $(56 \mathrm{mV}$ in pretest $1,52 \mathrm{mV}$ in pretest 2). However, the monosynaptic EPSP (elicited by a single action potential produced by intracellular current injection in an LE sensory neuron) in the same motor neuron showed considerable decrement $(5.6 \mathrm{mV}$ in pretest $1 ; 2.2 \mathrm{mV}$ in pretest 2). Strong tail shock recruited intense excitatory synaptic activity and spiking in the motor neuron, and a transient hyperpolarization in the sensory neuron. It is likely that the excitatory effects of tail shock in the siphon motor neurons are mediated by interneurons in the pedal and pleural ganglia (Cleary and Byrne, 1985), and perhaps in the abdominal ganglion, as well. The inhibitory effects of tail shock on the siphon sensory neurons are mediated, at least in part, by the identified inhibitory neuron L16, in the abdominal ganglion (Hawkins et al., 1981a; Wright and Carew, 1990).

In the first test after the tail shock, the complex EPSP was inhibited to less than a third of the preshock amplitude, from a baseline average of $56 \mathrm{mV}$ to $16 \mathrm{mV}$. In contrast, the monosynaptic EPSP was facilitated above the preshock levels, from a baseline average of $3.9 \mathrm{mV}$ to $6.0 \mathrm{mV}$. Finally, $10 \mathrm{~min}$ after 


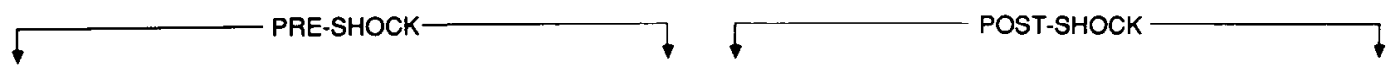

COMPLEXEPSP

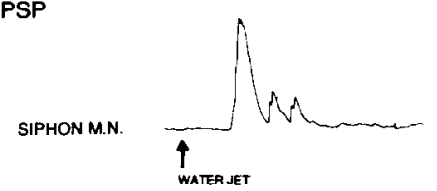

SIPHON M.N

SIPHON S.N.

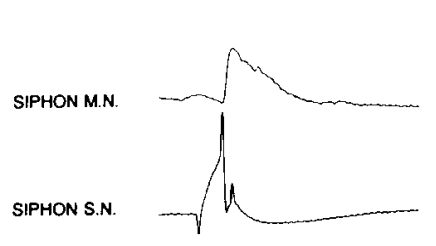

MONOSYNAPTIC EPSP

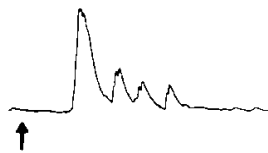

$\uparrow$

$$
\uparrow
$$
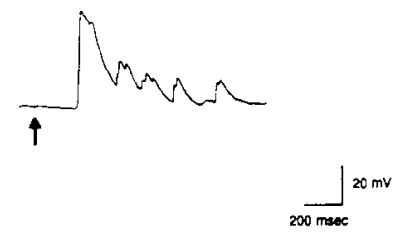
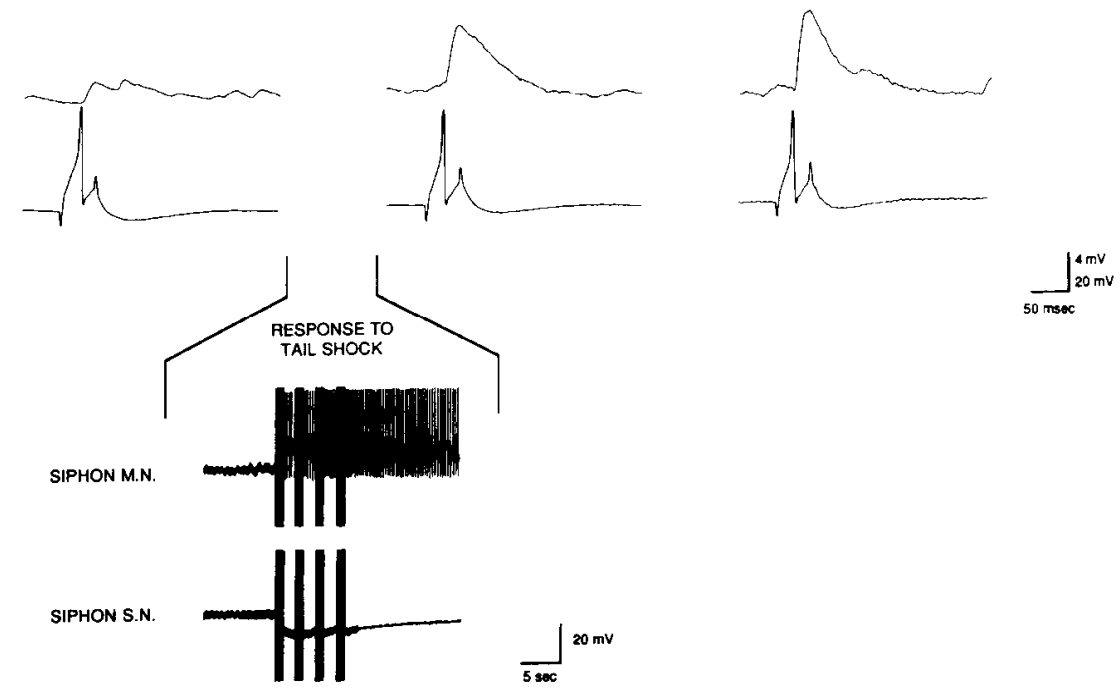

Figure 4. Tail shocked-induced modulation of the water jet-elicited complex EPSP and monosynaptic EPSP. The top row of traces shows the complex EPSPs in a siphon motor neuron (M.N.) in response to water jet stimuli (arrows) to the siphon. The bottom pairs of traces show the monosynaptic EPSP in the same motor neuron elicited by a single action potential (produced by intracellular current injection) in an LE sensory neuron $(S . N$.$) . Also shown are the responses of the motor and sensory neurons during the tail shock (inset). The dark vertical deflections in the$ inset traces are shock artifacts from four tail shocks in rapid succession. The complex EPSP is inhibited 90 sec after the shock (first test after shock) and recovers 10 min later (second test after shock). In contrast, the monosynaptic EPSP is facilitated both 120 sec (first test after shock) and 10 min (second test after shock) after the tail shock.

the tail shock, the complex EPSP recovered to preshock levels $(50 \mathrm{mV})$, whereas the monosynaptic EPSP was still elevated $(8.0$ $\mathrm{mV})$.

A summary of nine experiments in which complex and monosynaptic EPSPs were concurrently measured before and after strong tail shock is shown in Figure 5. Complex EPSPs were also measured in a control group in which tail shock was omitted $(N=7$; Fig. 5 ). As in the siphon withdrawal reflex, there was no significant difference between the amplitude of the complex EPSP in the two preshock tests (sign-rank test; $N=9 ; T^{+}=9$; $p=0.23$; data not shown). On the first test after strong tail shock (Fig. 5, test 1), the complex EPSP was significantly inhibited (median response, $62 \%$ below shock level; sign-rank test; $N=$ $\left.9, T^{+}=1 ; p=0.001\right)$. Moreover, a between-group comparison at test 1 revealed that the preparations receiving tail shock showed significant inhibition compared to the nonshocked control group (Wilcoxon two-sample; $N=9,7 ; W=51 ; p=0.008$ ). Finally, the amplitude of the complex EPSP recovered significantly by test 2 (Fig. 5; sign-rank test of test 2 vs test $1 ; N=9, T^{+}=40$; $p=0.044$; median, $17 \%$ below preshock level). Moreover, the amplitude of the complex EPSP at test 2 was statistically indistinguishable both from baseline (sign-rank test; $N=9, T^{+}=$ $11 ; p=0.13$ ) and from the nonshocked control group (twosample test; $N=9,7 ; W=77 ; p=1.0$ ).

The changes induced by tail shock in the monosynaptic EPSP (elicited by an action potential in an LE sensory neuron) did not parallel the changes observed in the complex EPSP (Fig. 5). Specifically, the monosynaptic EPSP was not inhibited in the first test after tail shock (sign-rank test; $N=9 ; T^{+}=30 ; p=$ 0.41 ), but rather tended to be above baseline (median, 136\%). Moreover, the relative amplitude of this elevated monosynaptic EPSP was significantly higher than that of the inhibited complex EPSP in the same test (Wilcoxon two-sample test; $W=58 ; p$ $=0.017$ ). Thus, the effect of tail shock on the monosynaptic EPSP was significantly different from the effeci of tail shock on the complex EPSP: the monosynaptic EPSP did not show the tail shock-induced inhibition observed in the complex EPSP.

In a separate set of experiments, we asked whether the inhibition of the complex EPSP in the siphon motor neuron could be accounted for by a change in the input resistance of the motor 


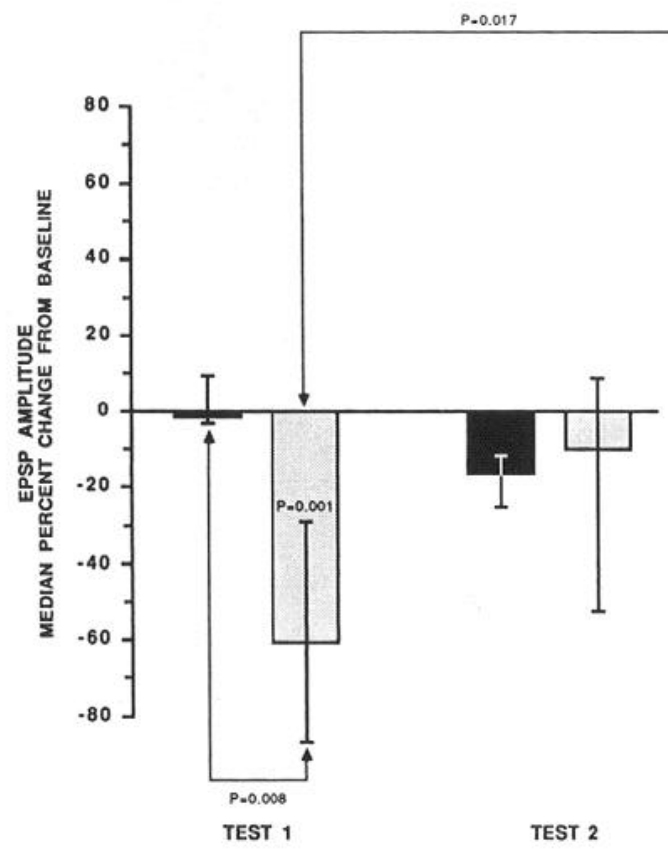

COMPLEX EPSP

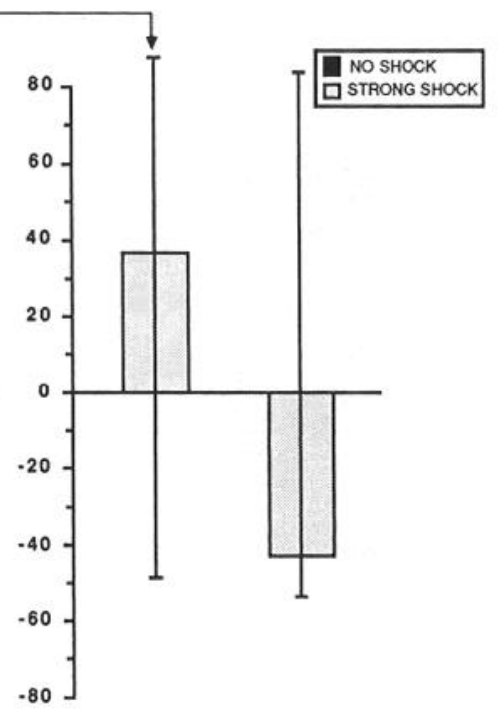

TEST 1 TEST 2

MONOSYNAPTIC EPSP
Figure 5. Summary of nondecremented synaptic responses. EPSP amplitude is expressed as percent change from the median of the two preshock responses. Significant inhibition and recovery are observed in the complex EPSP elicited by a water jet stimulus to the siphon, but no inhibition is observed in the monosynaptic postsynaptic potential $(N=9)$. The complex EPSP was significantly lower than preshock levels $90 \mathrm{sec}$ after tail shock (TEST 1) and recovers by TEST 2 . In contrast, $120 \mathrm{sec}$ after tail shock, the monosynaptic EPSP tended to be higher (TEST 1). Moreover, the relative changes in the complex and monosynaptic EPSPs at Test 1 were significantly different. The complex EPSP recovered significantly by the 10 -min test. neuron. To examine this question, in 11 preparations, a 500msec pulse of hyperpolarizing current $(0.25 \mathrm{nA})$ was injected into the motor neuron just prior to each water jet stimulus to the siphon, and the resulting electrotonic potential was measured. Two pretests and two postshock tests were conducted. The results are shown in Figure 6. As in the previous experiment, the complex EPSP was significantly inhibited $90 \mathrm{sec}$ after strong tail shock (median, $20 \mathrm{mV}, 53 \%$ of baseline; sign-rank test; $N$ $\left.=11 ; T^{+}=6 ; p=0.018\right)$. In the same experiments, input resistance at test 1 (when the complex EPSP was inhibited) was not significantly different from pretest levels (median pretest level, $32 \mathrm{M} \Omega$; median postshock level, $32 \mathrm{M} \Omega, 100 \%$ of baseline; sign-rank test; $\left.N=11 ; T^{+}=22 ; p=1.0\right)$. These data support the hypothesis that the inhibition of the complex EPSP is not due to a decrease in the input resistance of the siphon motor neurons. To test this hypothesis fully, one should examine possible changes in resistance across a wide range of membrane potentials. Nonetheless, these preliminary observations suggest that the primary locus of inhibition is presynaptic to the motor neurons (see Discussion).

In summary, the behavioral inhibition induced by strong tail shock in the nondecremented reflex was closely paralleled by inhibition observed in the net complex synaptic input to siphon motor neurons, but was not paralleled by inhibition of the monosynaptic connection between siphon sensory and siphon motor neurons.
A

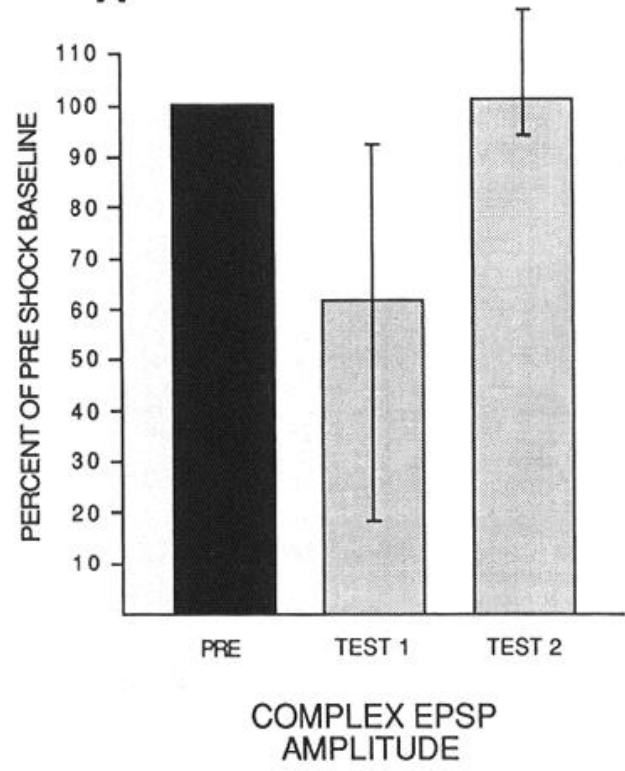

B

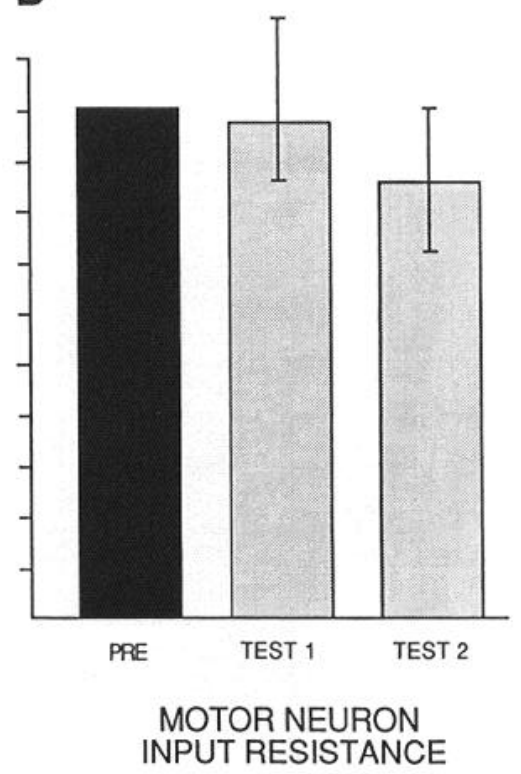

Figure 6. Inhibition of the complex EPSP is not accompanied by a change in input resistance of the motor neuron. $A$, Summary data showing the amplitude of the complex EPSP before (solid bar) and after (shaded bars) tail shock. As in previous experiments, the complex EPSP is significantly inhibited 90 $\sec ($ TEST 1) after tail shock and recovers by $10 \mathrm{~min}$ (TEST 2). B, The input resistance of the siphon motor neuron is not significantly different from baseline at TEST 1 when the complex EPSP is inhibited. There is a modest but significant reduction in input resistance at the 10-min test (TEST 2), but this occurs when the complex EPSP has completely recovered from inhibition. 


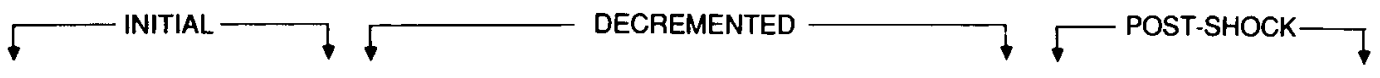

COMPLEX EPSP
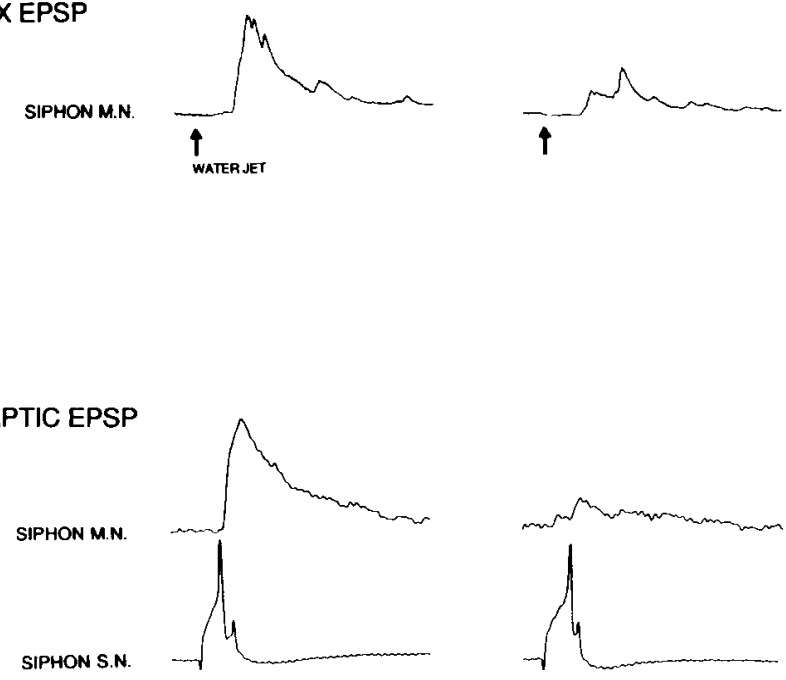
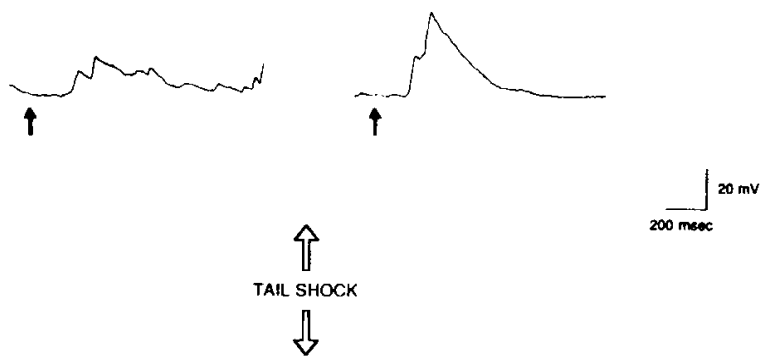

MONOSYNAPTIC EPSP

Figure 7. Effect of weak tail shock on decremented EPSPs. When first decremented by repeated stimuli, both complex and monosynaptic EPSPs are facilitated by weak tail shock. The top row of traces shows complex EPSPs elicited in a siphon motor neuron (M.N.) by water jet stimuli (arrows) to the siphon. The bottom pairs of traces show monosynaptic EPSPs in the same motor neuron elicited by a single action potential in a siphon sensory neuron (S.N.). Complex EPSPs were decremented by repeated water jet stimuli; monosynaptic EPSPs were decremented by repeated single spikes in a sensory neuron elicited by intracellular current injection (100-sec ISI for both). Responses to the first (INITIAL), 19th, 20th (DECRE$M E N T E D)$, and 21 st (POST-SHOCK) stimuli are shown. Also shown are the responses in the motor neuron and sensory neuron during the tail shock (inset). Both decremented complex and monosynaptic EPSPs were facilitated by weak tail shock.

\section{Decremented responses}

We next examined the effects of weak and strong tail shock on decremented complex and monosynaptic EPSPs, in order to establish a neural correlate of our behavioral data demonstrating that weak shock produces dishabituation of the reflex response, whereas strong tail shock does not.

An example of our results with weak tail shock is shown in Figure 7 . Twenty stimuli delivered at a $100-\mathrm{sec}$ interval produced synaptic decrement of both the complex EPSP and the monosynaptic EPSP, which paralleled behavioral habituation: the initial complex EPSP was $47 \mathrm{mV}$, and decremented to 22 and $18 \mathrm{mV}$ on trials 19 and 20 , respectively; likewise, the initial monosynaptic EPSP was $8.0 \mathrm{mV}$, and decremented to 1.6 and $3.8 \mathrm{mV}$ on trials 19 and 20, respectively. Both complex and monosynaptic EPSPs showed facilitation $90 \mathrm{sec}$ after a weak electric shock to the tail (the complex EPSP facilitated to 42 $\mathrm{mV}$; the monosynaptic EPSP, to $4.2 \mathrm{mV}$ ). Thus, both decre- mented monosynaptic and complex EPSPs showed facilitation after weak shock that paralleled dishabituation to weak shock in behavioral experiments.

An example of our results examining the effects of strong shock on decremented synaptic responses is shown in Figure 8. Again, both complex EPSPs and monosynaptic EPSPs showed synaptic decrement (complex EPSP, from an initial valuc of 34 $\mathrm{mV}$ to 16 and $17 \mathrm{mV}$ on trials 19 and 20 , respectively; monosynaptic EPSP, from $1.4 \mathrm{mV}$ to 0.3 and $0.8 \mathrm{mV}$ on trials 19 and 20, respectively). After strong tail shock, the complex EPSP remained at approximately its preshock (decremented) level (20 $\mathrm{mV}$ ). In contrast, the decremented monosynaptic EPSP was facilitated more than twofold (to $1.8 \mathrm{mV}$ ).

The median EPSP amplitudes from 10 experiments using weak shock and 10 experiments using strong shock are shown in Figure 9. Consistent with the effects observed for the siphon withdrawal reflex in the intact and reduced preparations, after weak shock both complex and monosynaptic EPSPs were fa- 


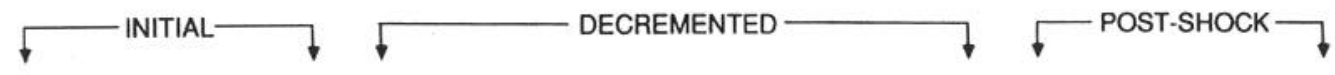

COMPLEX EPSP

SIPHON M.N.

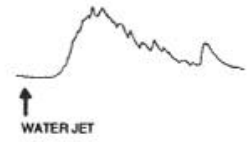

MONOSYNAPTIC EPSP

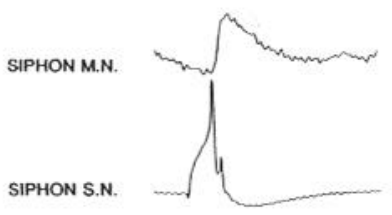

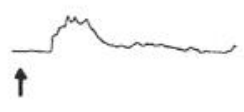

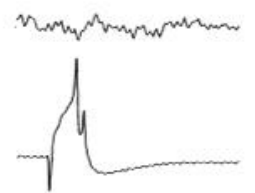

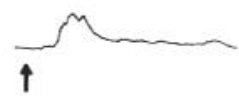
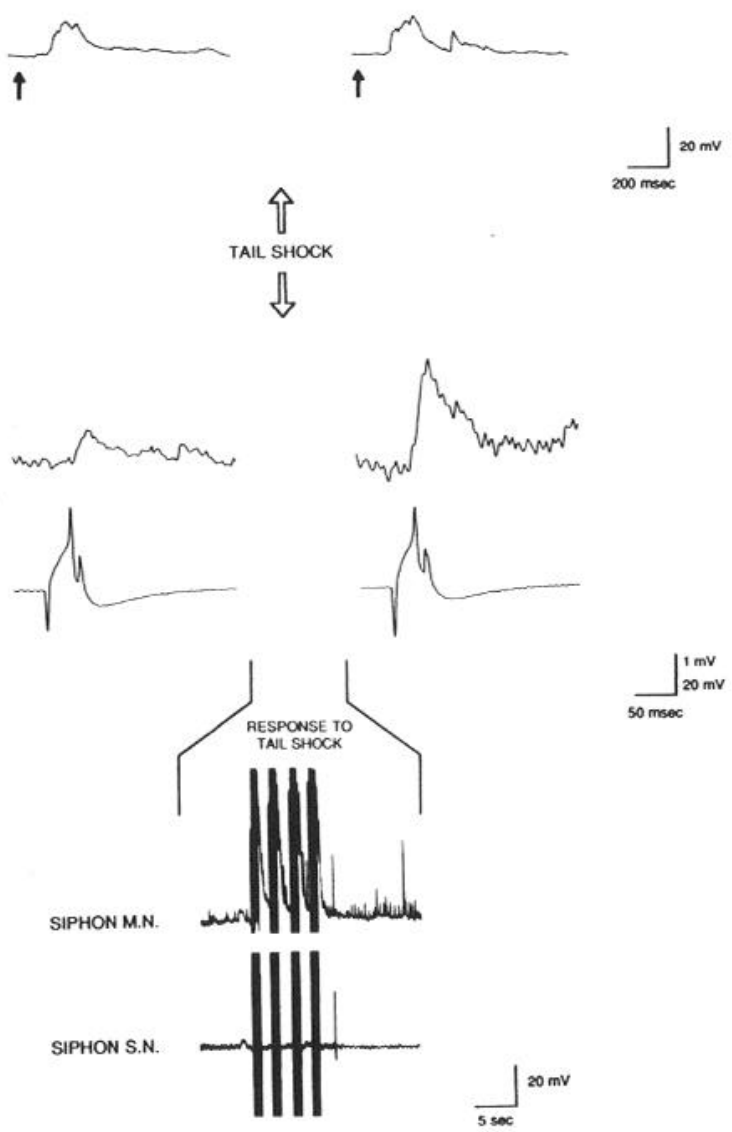

Figure 8. Effect of strong tail shock on decremented EPSPs. In contrast to weak tail shock, the decremented complex EPSP is not facilitated by strong tail shock, whereas the decremented monosynaptic EPSP is clearly facilitated by strong tail shock. See Figure 6 caption for details.

cilitated over their decremented baselines (complex EPSP: median, $127 \%$; sign-rank test; $N=10 ; T^{+}=50 ; p=0.025$; monosynaptic EPSP: median, $167 \%$; sign-rank test; $N=9 ; T^{+}=38$; $p=0.038$, one-tailed). The changes from baseline of the complex and monosynaptic EPSPs after weak shock were not significantly different from each other (two-sample test; $N=9,10 ; W=88$; $p=0.348$ ), suggesting that weak tail shock had a similar facilitatory effect on both synaptic responses. However, after strong tail shock, only the complex EPSP paralleled the behavior, showing no significant change from its decremented baseline (median, 110\%; sign-rank test; $N=10 ; T^{+}=40 ; p=0.22$ ). In contrast, the decremented monosynaptic EPSP was significantly facilitated (median, 188\%; sign-rank test; $N=9 ; T^{+}=35 ; p=$ 0.021 ) by strong shock. Furthermore, the relative amplitude of the monosynaptic EPSP tended to be higher than that of the complex EPSP (two-sample test; $W=76 ; p=0.055$ ).

In summary, paralleling the effects of tail shock on the siphon withdrawal reflex, weak tail shock significantly facilitated decremented complex EPSPs, whereas strong tail shock failed to produce facilitation. This inverse relationship between the degree of facilitation and tail shock intensity was not observed for the decremented monosynaptic EPSP.

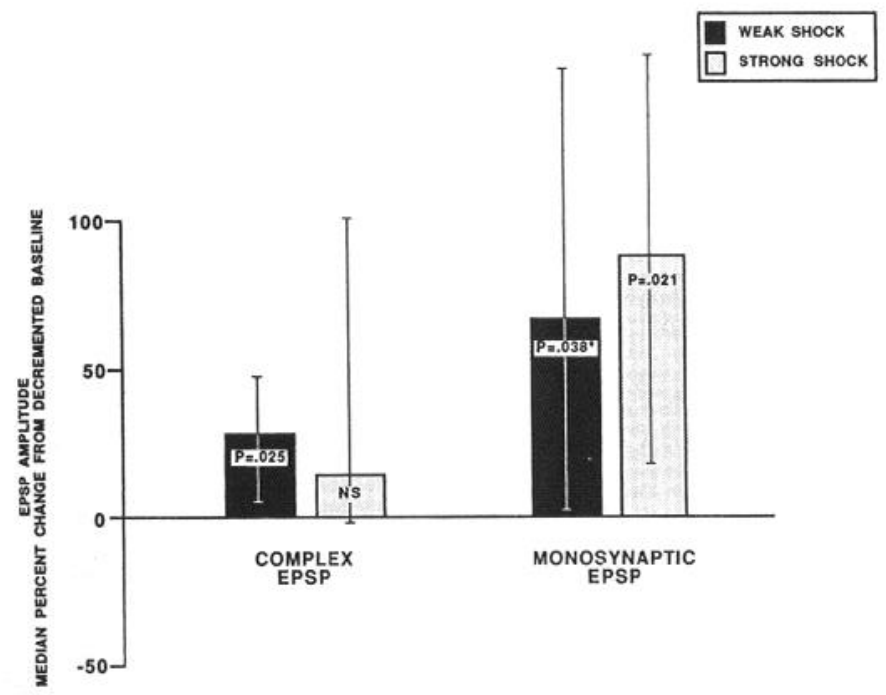

Figure 9. Summary of decremented synaptic responses. EPSP amplitude is expressed as percent change from the median of the last three responses (trials 18-20) before the tail shock. Decremented complex EPSPs were significantly facilitated by weak but not by strong tail shock. In contrast, decremented monosynaptic EPSPs were facilitated by both weak and strong tail shock. The asterisk indicates a one-tailed probability level. 

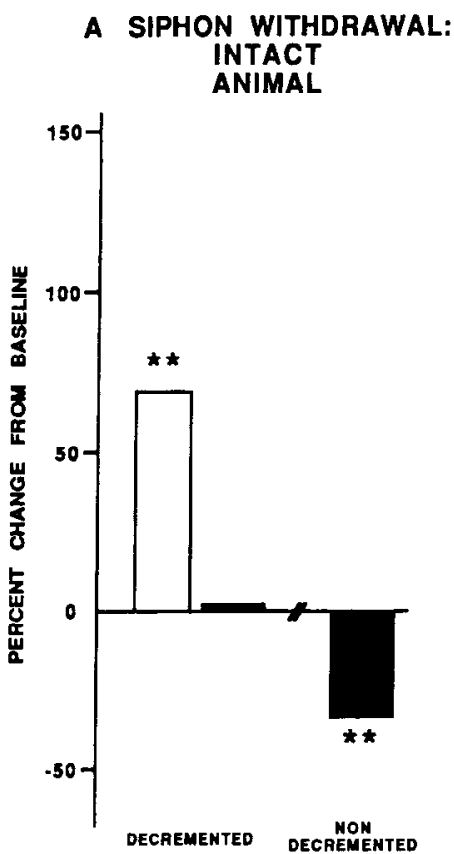

B SIPHON WITHDRAWAL: REDUCED PREPARATION

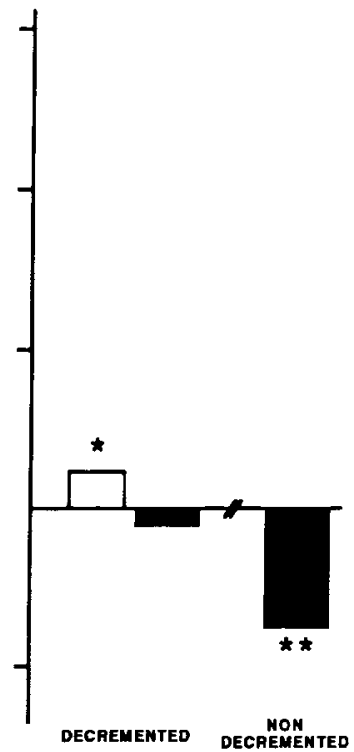

C COMPLEX EPSP: REDUCED PREPARATION

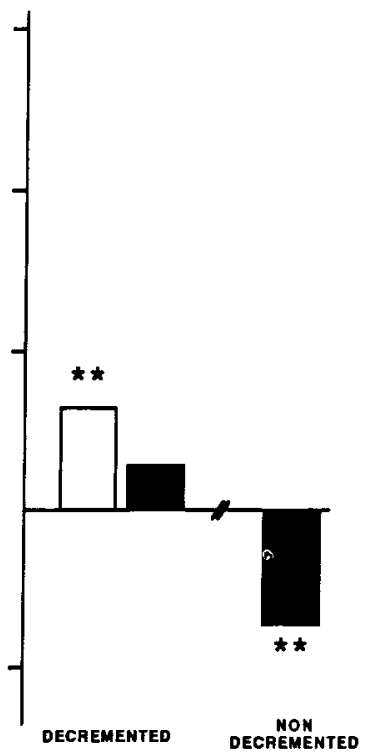

D MONOSYNAPTIC EPSP: REDUCED PREPARATION

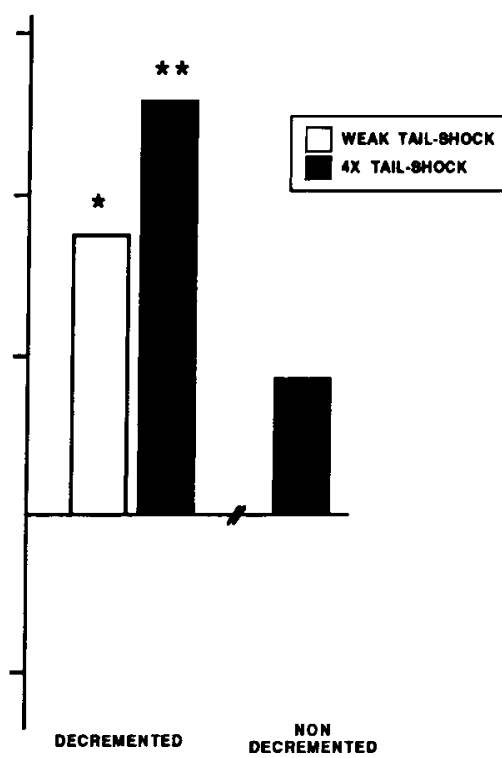

Figure 10. Comparison of the effects of tail shock at different levels of analysis. For comparative purposes, all responses are expressed as percent change in response amplitude at test 1 (90-120 sec after tail shock). Strong shock is indicated by solid bars; weak shock as open bars. Asterisks indicate within-group probability levels $\left(^{*}\right.$, one-tailed probability, $p<0.05$; ${ }^{* *}$, two-tailed probability, from $p<0.05$ to $p<0.001$ ).

A

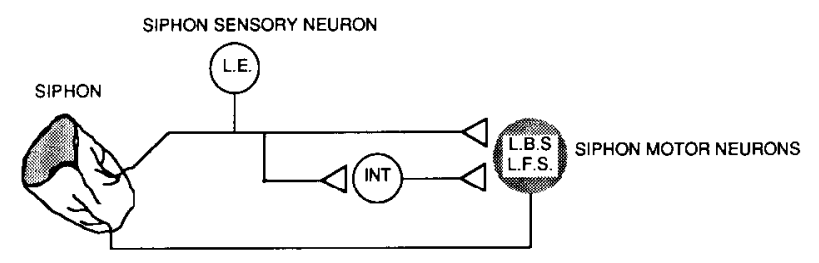

SIPHON SENSORY NEURON

B
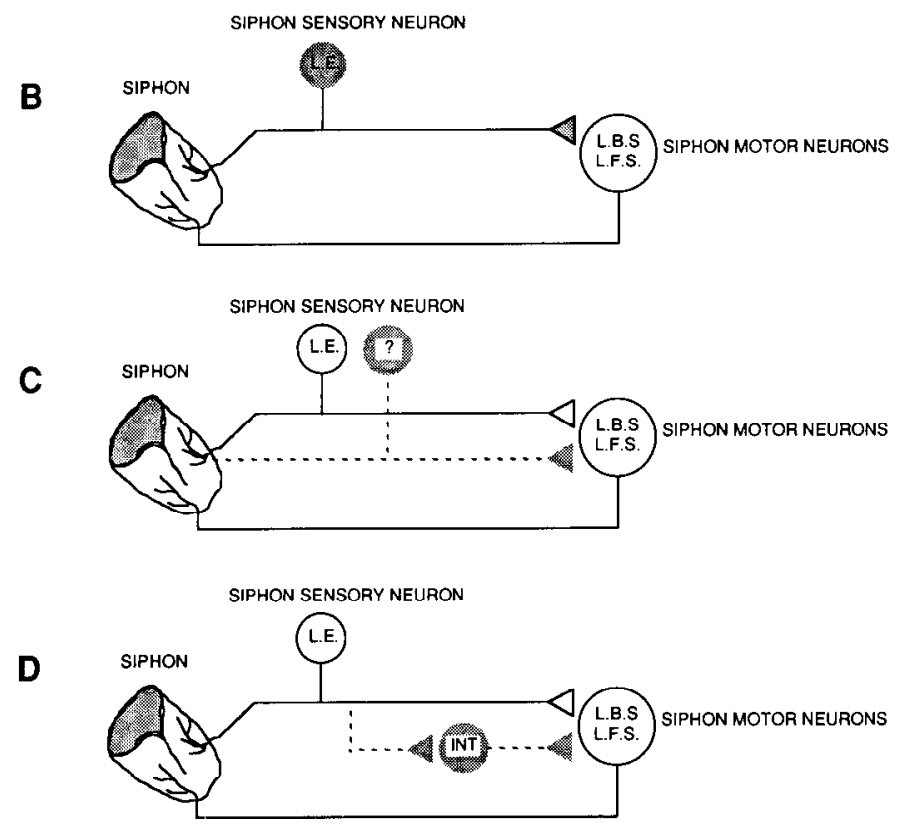

Figure 11. Schematic representation of four classes of possible cellular loci (indicated by shading) underlying tail shock-induced inhibition of the siphon withdrawal reflex. See Discussion for details.

\section{Discussion}

Neuronal correlates of inhibition in the siphon withdrawal reflex

The primary goal of the present work was to explore the neural basis of tail shock-induced inhibitory modulation in the siphon withdrawal reflex in Aplysia. In these experiments, we employed a reduced preparation that allowed using the same stimuli that were used in the intact animal (Marcus et al., 1988): water jet stimuli to the siphon to elicit the reflex, and tail shock to modulate the reflex. In order to identify neural correlates of inhibition in the neural circuit for siphon withdrawal, we examined two different sources of synaptic input onto siphon motor neurons: the complex EPSP elicited by water jet stimuli to the siphon, and the monosynaptic EPSP elicited by an action potential in a siphon sensory neuron.

Our results are summarized in Figure 10, which compares the effect of tail shock on decremented and nondecremented responses in the siphon withdrawal reflex of the intact animal, the siphon withdrawal reflex of the reduced preparation, the complex EPSP in siphon motor neurons, and the monosynaptic connection between LE sensory neurons and the siphon motor neurons. In the intact animal (Fig. 10A; redrawn from Marcus et al., 1988), strong tail shock produces significant inhibition of the nonhabituated (nondecremented) siphon withdrawal reflex. The same strong tail shock fails to produce facilitation of habituated responses, suggesting the recruitment of an inhibitory process that competes with the facilitation produced by weak shock. This pattern (inhibition of nondecremented responses and a reduction in the amount of facilitation in the decremented responses) is paralleled in the reduced preparation, both at the level of the behavioral reflex and at the level of the complex EPSP elicited by water jet stimuli (Fig. 10B,C). In contrast, tail 
shock-induced modulation in the monosynaptic connection between siphon sensory and siphon motor neurons does not reflect the inhibitory pattern (Fig. 10D): at a time when the siphon withdrawal reflex and the complex EPSP are inhibited, strong tail shock produces no inhibition of noncremented monosynaptic EPSPs, and facilitation after strong shock is at least as great as after weak shock.

The data summarized in Figure 10 show that tail shock can produce opposite effects in complex and monosynaptic EPSPs in siphon motor neurons. Tail shock activates tail sensory neurons in the pleural ganglia (Walters et al., 1983a,b), which in turn modulate the siphon withdrawal reflex through interneuronal pathways. For example, it is known that tail shock can activate serotonergic interneurons that project to the neural circuit for siphon withdrawal (Mackey et al., 1989). These observations raise the question of whether 5-HT, like tail shock, can also differentially affect synaptic inputs to siphon motor neurons. Fitzgerald and Carew (1991) have examined this issue and found that 5-HT can in fact inhibit the complex EPSP in siphon motor neurons, as well as the siphon withdrawal reflex, while simultaneously facilitating the monosynaptic EPSP from siphon sensory neurons. Thus, the dissociation of inhibition and facilitation produced by tail shock in the neural circuit for siphon withdrawal (Fig. 10) is mimicked by the neuromodulator 5-HT . When the cellular loci of tail shock-induced inhibition are identified, it will be interesting to examine whether 5-HT will similarly mimic the effects of tail shock at these sites.

\section{Possible neuronal sites mediating the inhibitory process}

In considering inhibition in the siphon withdrawal reflex, four broad classes of hypotheses about the cellular locus of the inhibitory process can be considered. These are schematically illustrated in Figure 11, We will discuss each of these hypotheses in light of our present results.

The first hypothesis is that the inhibition is produced by changes in the input resistance of the motor neuron (Fig. 11A). Spccifically, tail shock could induce a large decrease in the input resistance of the motor neuron, which would shunt the synaptic current generated by the reflex input, thereby reducing the complex EPSP. Two lines of evidence suggest that this hypothesis is not likely to account for the inhibition: (1) the input resistance in the motor neuron (as measured by electrotonic potentials produced by current injected into the soma) does not change during the inhibition of the complex EPSP, and (2) following tail shock, when the complex EPSP is reduced, the monosynaptic EPSP is simultaneously increased. Thus, though it is possible that remote changes in input resistance could, in principle, contribute to inhibition of the complex EPSP, our results favor the idea that the principal site(s) of inhibition is presynaptic to the motor neuron.

The second hypothesis is that the direct monosynaptic connection between LE siphon sensory neurons and siphon motor neurons is diminished immediately following tail shock, so that it contributes less to the total synaptic input onto the motor neurons (Fig. 11B). Mackey et al. (1987) observed a decrease in this monosynaptic EPSP immediately after tail shock. However, the inhibition they observed gave way to facilitation by $90 \mathrm{sec}$ after shock, whereas the behavioral inhibition persisted at least 2.5 min after shock. Thus, as Mackey et al. (1987) point out, there was a discrepancy between the time course of behavioral inhibition and the reduction in transmitter release from the LE sensory neurons. This discrepancy suggests that modu- lation of the monosynaptic connection between LE sensory neurons and siphon motor neurons cannot, by itself, account for the behavioral inhibition observed in the siphon withdrawal reflex.

The results of the present study, in which the monosynaptic connection was monitored simultaneously with the water jetelicited complex EPSP in siphon motor neurons, indicate that the inhibitory patterns observed in the complex EPSP are not paralleled by changes in the monosynaptic EPSP. First, $90 \mathrm{sec}$ after strong tail shock, when the behavioral reflex and the complex EPSP show significant inhibition, the monosynaptic EPSP is not inhibited; rather, consistent with the observations of Mackey et al. (1987), it tends to be facilitated. Second, the absence of facilitation of decremented responses after strong shock, which we observed in the reflex and the complex EPSP, was not observed in the monosynaptic connection. Indeed, strong tail shock produced a twofold facilitation of the decremented monosynaptic connection at the same time that the decremented complex EPSP showed no facilitation. Taken together, these results indicate that the monosynaptic connection between LE sensory neurons and siphon motor ncurons cannot by itsclf account for tail shock-induced inhibition of either the water jet-elicited complex EPSP, or the siphon withdrawal reflex.

Although the tail shock-induced inhibition of the siphon withdrawal reflex we observed at $90 \mathrm{sec}$ cannot be accounted for by inhibition of the monosynaptic connection, it is known from work by Mackey et al. (1987) that this synapse is inhibited for about $30 \mathrm{sec}$ following tail shock. R. D. Hawkins and E. R. Kandel (personal communication) have recently found that, in the gill withdrawal reflex, tail shock-induced inhibition is more short-lived than in the siphon withdrawal reflex. Thus, the time course of inhibition in the gill withdrawal reflex is more closely paralleled by inhibition of the monosynaptic connection. This observation raises the possibility that the short-lasting reduction in transmitter release from the sensory neurons produced by tail shock (Mackey et al., 1987) contributes more to inhibition of gill withdrawal than to that of siphon withdrawal. The broader implication of this possibility is that the neural circuits for the siphon withdrawal reflex and the gill withdrawal reflex, as well as plasticity within these circuits, may be less similar than previously appreciated. It will therefore be of interest to examine the inhibitory process induced by tail shock, as well as other forms of modulation, simultaneously in the circuits for siphon withdrawal and gill withdrawal.

It is also possible that tail shock-induced increases in transmitter release from LE sensory neurons onto some of their follower cells could contribute indirectly to the net inhibition of the complex EPSP in the siphon motor neurons. For example, if after tail shock the functional connections between LE sensory neurons and inhibitory interneurons (Hawkins et al., 1981a; Frost et al., 1988) were increased more than the connections to excitatory interneurons, then the increase in synaptic transmission from the sensory neurons could, in principle, play a significant role in mediating tail shock-induced inhibition.

A third hypothesis for the locus of inhibition is illustrated in Figure $11 C$, which suggests the possibility that another (as yet unidentified) set of sensory neurons may be modulated by tail shock in ways consistent with the inhibition we observed in both the complex EPSP and the behavior. Such a possibility is supported by recent observations of Rosen and colleagues (Rosen et al., 1989), who examined sensory neurons in the cerebral ganglion of Aplysia. They showed that different classes of sensory 
neurons responded oppositely to the same modulatory inputs: nerve shock or 5-HT application produced spike broadening and enhanced synaptic release in one class of sensory neurons, while simultaneously producing spike narrowing and diminished synaptic release in another class. Moreover, Dubuc and Castellucci (1991) have recently described several new populations of sensory neurons in the abdominal ganglion. While some of these new sensory neurons closely resemble the LE sensory neurons in their sensitivity to a variety of neuromodulators, others do not. Thus, we are currently examining the possibility that another set of sensory neurons in the siphon withdrawal reflex may contribute to the inhibitory process that we observe.

A fourth hypothesis for the locus of inhibition is illustrated in Figure $11 \mathrm{D}$, which suggests the possibility that plasticity at central interneurons might contribute significantly to the inhibitory process. Many interneurons (both excitatory and inhibitory) that have a role in mediating the siphon withdrawal reflex have already been identified (Hawkins et al., 1981a,b; Frost et al., 1988; Frost and Kandel, 1990). The synaptic efficacy of these cells, as well as that of other as yet unidentified interneurons, may be altered by tail shock in ways that contribute to inhibition of the complex EPSP. For example, Hawkins et al. (1981b) first showed that intracellular activation of an identified inhibitory interneuron (L16) can inhibit the complex EPSP elicited by siphon nerve shock. We have recently found that intracellular activation of L16 also inhibits the complex EPSP elicited by water jet stimuli to the siphon (Wright and Carew, 1990). Furthermore, we have found that tail shock produces strong spike activity in L16. Finally, hyperpolarizing or voltage clamping L16 (which prevents its firing in response to tail shock) significantly diminishes or abolishes the inhibition of the complex EPSP produced by tail shock (Wright and Carew, 1990; W. G. Wright and T. J. Carew, in preparation). Thus, L16, as well as other interneurons, may play a significant role in the reflex inhibition we observe.

In conclusion, our results show that different functional elements underlying a single reflex can be simultaneously modulated in opposing ways. Important insights into the cellular and subcellular basis of behavioral facilitation in the siphon withdrawal reflex have already been obtained (for review, see Byrne, 1987; Carew, 1987; Hawkins et al., 1987). Once the sites that mediate inhibition in the siphon withdrawal reflex have been identificd, it will be of considerable interest to examine similarly the cellular and subcellular mechanisms underlying the inhibition. Moreover, to understand fully the neuronal basis of tail shock-induced modulation in the reflex, it will be important to analyze how the nervous system integrates opposing modulatory changes to produce the net reflex output observed at motor neuronal and behavioral levels. This question of integration of opposing signals by cells within a circuit is analogous to questions that have arisen from intensive study of integration within single cells (see, e.g., Abrams and Kandel, 1988). For example, within a single sensory neuron in Aplysia, second-messenger systems with opposing biophysical effects can be simultaneously activated by modulatory stimuli such as tail shock (Belardetti et al., 1987; Mackey et al., 1987; Piomelli et al., 1987). The results of the present study lend emphasis to the suggestion that an analysis of the principles of integration both within individual neurons and between neurons in a functional neural circuit may provide insights into the mechanisms underlying learning and memory.

\section{References}

Abrams TW, Kandel ER (1988) Is contiguity detection in classical conditioning a system or a cellular property? Learning in Aplysia suggests a possible molecular site. Trends Neurosci 11:128-135.

Baxter DA, Byrne JH (1989) Serotonergic modulation of two potassium currents in the pleural sensory neurons of Aplysia. J Neurophysiol 62:665-679.

Belardetti F, Kandel ER, Siegelbaum SA (1987) Neuronal inhibition by the peptide FMRFamide involves opening of $\mathrm{S} \mathrm{K}^{+}$channels. $\mathrm{Na}-$ ture 325:153-156.

Bernier L, Castellucci VF, Kandel ER, Schwartz JH (1982) Facilitatory transmitter causes a selective and prolonged increase in adenosine $3^{\prime}$ : $5^{\prime}$-monophosphate in sensory neurons mediating the gill and siphon withdrawal reflex in Aplysia. J Neurosci 2:1682-1691.

Byrne JH (1987) Cellular analysis of associative learning. Physiol Rev $67: 329-439$.

Byrne JH, Castellucci VF, Kandel ER (1974) Receptive fields and response properties of mechanoreceptor neurons innervating skin and mantle shelf of Aplysia. J Neurophysiol 37:1041-1064.

Carew TJ (1987) Cellular and molecular advances in the study of learning in Aplysia. In: The neural and molecular basis of learning (Changeaux JP, Konishi M, eds), pp 177-204. New York: Wiley.

Cleary LJ, Byrne JH (1985) Interneurons contributing to the mediation and modulation of the tail withdrawal reflex in Aplysia. Soc Neurosci Abstr 11:642.

Dubuc B, Castellucci VF (1991) Receptive fields and properties of a new cluster of mechanoreceptor ncurons innervating the mantle region and branchial cavity of the marine mollusc Aplysia californica. J Exp Biol 156:315-334.

Fitzgerald KF, Carew TJ (1991) Serotonin mimics tail shock in producing transient inhibition in the siphon withdrawal reflex of Aplysia. J Neurosci 11:2510-2518

Frost WN, Kandel ER (1990) Further characterization of interneurons and motor neurons in the siphon withdrawal reflex circuit in Aplysia californica. J Neurophysiol, in press.

Frost WN, Clark GA, Kandel ER (1988) Parallel processing of shortterm memory for sensitization in Aplysia. J Neurobiol 19:297-334.

Hawkins RD, Castellucci VF, Kandel FR (1981a) Interneurons involved in mediation and modulation of gill-withdrawal reflex in $A p l y-$ sia. I. Identification and characterization. J Neurophysiol 45:304314.

Hawkins RD, Castellucci VF, Kandel ER (1981b) Interneurons involved in mediation and modulation of gill-withdrawal reflex in $A p l y$ sia. II. Identified neurons produce heterosynaptic facilitation contributing to behavioral sensitization. J Neurophysiol 45:315-326.

Hawkins RD, Clark GA, Kandel ER (1987) Cell biological studies of learning in simple vertebrate and invertebrate systems. In: Handbook of physiology, Sect I, Higher functions of the nervous system, Vol 6 (Plum F, ed), pp 25-83. Bethesda, MD: American Physiological Society.

Hollander M, Wolfe DA (1973) Non-parametric statistical methods. New York: Wiley.

Kandel ER, Schwartz JH (1982) Molecular biology of learning: modulation of transmitter release. Science 218:433-443.

Klein M, Kandel ER (1980) Mechanism of calcium current modulation underlying presynaptic facilitation and behavioral sensitization in Aplysia. Proc Natl Acad Sci USA 77:6912-6916.

Krontiris-Litowitz JK, Erikson MT, Walters ET (1987) Central suppression of defensive reflexes in Aplysia by noxious stimulation and by factors released from the body wall. Soc Neurosci Abstr 13:815.

Mackey SL, Glanzman DL, Small SA, Dyke AM, Kandel ER, Hawkins RD (1987) Aversive stimuli produce inhibition as well as sensitization of the siphon withdrawal reflex of Aplysia: a possible behavioral role for presynaptic inhibition mediated by the peptide FMRFamide. Proc Natl Acad Sci USA 84:8730-8734.

Mackey SL, Kandel ER, Hawkins RD (1989) Identified serotonergic neurons LCB1 and RCBI in the cerebral ganglia of Aplysia produce presynaptic facilitation of siphon sensory neurons. J Neurosci 9:42274235 .

Mackintosh NJ (1974) Conditioning and associative learning. New York: Academic.

Marcus EA, Nolen TG, Rankin CH, Carew TJ (1987) Behavioral dissociation of dishabituation, sensitization and inhibition in the siphon withdrawal reflex of adult Aplysia. Soc Neurosci Abstr 13:816. 
Marcus EA, Nolen TG, Rankin CH, Carew TJ (1988) Behavioral dissociation of dishabituation, sensitization, and inhibition of Aplysia. Science 241:210-213.

Occor KA, Tabata M, Byrne JH (1986) Stimuli that produce sensitization lead to elevation of cyclic AMP levels in tail sensory neurons of Aplysia. Brain Res 371:190-192.

Piomelli D, Shapiro E, Feinmark SJ, Schwartz JH (1987) Metabolites of arachodonic acid in the nervous system of Aplysia: possible mediators of synaptic modulation. J Neurosci 7:3675-3686.

Rankin CH, Carew TJ (1987) Analysis of the developmental emergence of sensitization in Aplysia reveals an inhibitory effect of a facilitatory stimulus. Soc Neurosci Abstr 13:816.

Rankin CH, Carew TJ (1989) Developmental analysis in Aplysia reveals inhibitory as well as facilitatory effects of tail shock. Behav Neurosci 103:334-344.

Rosen SC, Susswein AJ, Cooper EC, Weiss KR, Kupferman I (1989) Selective modulation of spike duration by serotonin and the neuropeptides FMRFamide, $\mathrm{SCP}_{\mathrm{B}}$, buccalin and myomodulin in different classes of mechanoafferent neurons in the cerebral ganglion of Aplysia. J Neurosci 9:390-402.

Siegelbaum SA, Camardo JS, Kandel ER (1982) Serotonin and cyclic
AMP close single $\mathrm{K}^{+}$channels in Aplysia sensory neurons. Nature 299:413-417.

Walsh JP, Byrne JH (1989) Modulation of a steady-state $\mathrm{Ca}^{2+}$-activated $\mathrm{K}^{+}$current in tail sensory neurons of $A$ plysia: role of serotonin and cAMP. J Neurophysiol 61:32-44.

Walters ET, Byrne JH, Carew TJ, Kandel ER (1983a) Mechanoafferent neurons innervating the tail of Aplysia. I. Response properties and synaptic connections. J Neurophysiol 50:1522-1542.

Walters ET, Byrne JH, Carew TJ, Kandel ER (1983b) Mechanoafferent neurons innervating the tail of Aplysia. II. Modulation by sensitizing stimuli. J Neurophysiol 50:1543-1559.

Wright WG, Carew TJ (1990) Contributions of interneurons to tailshock induced inhibition of the siphon withdrawal reflex in Aplysia. Soc Neurosci Abstr 16:20.

Wright WG, Marcus EA, Thaker H, Carew TJ (1988) A cellular analysis of tail-shock induced inhibition in the siphon withdrawal reflex of Aplysia. Soc Neurosci Abstr 14:841.

Wright WG, Marcus EA, Carew TJ (1989) Dissociation of monosynaptic and polysynaptic contributions to dishabituation, sensitization and inhibition in Aplysia. Soc Neurosci Abstr 15:1265. 